\title{
Evaluation of the Efficacy of Low-Dose Acetylsalicylic Acid (Aspirin) in Prevention of Pre-Eclampsia in High-Risk Pregnant Women
}

\author{
Dr. Naimisha Movva ${ }^{1}$, Dr. Manjari Hota ${ }^{2 *}$ \\ ${ }^{1}$ Assistant Professor, Department of Obstetrics and Gynaecology of Mamata Medical College and General Hospital, Khammam, Telangana, India \\ ${ }^{2}$ Senior Resident, Department of Obstetrics and Gynaecology of Mamata Medical College and General Hospital, Khammam, Telangana, India
}

DOI: $10.36348 /$ sijog.2020.v03i10.001 | Received: 12.10 .2020 | Accepted: 25.10.2020 | Published: 30.10 .2020

*Corresponding author: Dr. Manjari Hota

Abstract

Background: Pre-eclampsia affects up to $10 \%$ pregnancies worldwide and is one of the foremost causes of poor maternal and foetal outcome. The situation in India is even grave with high rate of maternal mortality due to pre-eclampsia. Though multiple risk factors are associated with pre-eclampsia, it is known that first pregnancy itself is a significant preeclamptic risk factor. Therefore, in this study we intent to gauge the effects of low dose Acetyl salicylic acid (Aspirin) among pregnant women in prevention of pre-eclampsia. Materials and Methods: This randomized controlled study was conducted in Department of Obstetrics and Gynaecology of Mamata Medical College and General Hospital. Total 100 patients were enrolled in this study. Pregnant women with and without any other pre-eclamptic risk factor consulting before the 16th week of amenorrhea were selected in the study. One group i.e. Treatment group ( $\mathrm{n}=50)$ was given $75 \mathrm{mg} /$ day aspirin orally after breakfast to one week before estimated date of delivery while the other group received no aspirin. Both groups were followed for regular antenatal check-up. Results: The treatment group who received acetyl

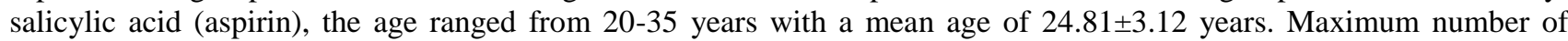
cases belonged wot age group of 26-30 years. The treatment group who received acetyl salicylic acid (aspirin), the age ranged from 20-35 years with a mean age of 25.21 \pm 4.29 years. Moreover, we found pre-eclampsia in aspirin group was of lesser severity as compared to those in control group. Further, proportion wise the risk of pregnancy induced hypertension and eclampsia were also reduced with aspirin, however, these were not found statistically significant. Conclusion: Our study highlights the beneficial effect of low-dose acetyl salicylic acid in decreasing hypertension and proteinuria. This study also confirms the efficacy of acetyl salicylic acid in decreasing caesarean section, maternal mortality and morbidity.

Keywords: Acetyl salicylic acid (aspirin), pregnancy, preeclampsia, maternal mortality.

Copyright (C) 2020 The Author(s): This is an open-access article distributed under the terms of the Creative Commons Attribution 4.0 International License (CC BY-NC 4.0) which permits unrestricted use, distribution, and reproduction in any medium for non-commercial use provided the original author and source are credited.

\section{INTRODUCTION}

Acetyl salicylic acid (Aspirin) is currently the most widely prescribed treatment in the prevention of cardiovascular complications. The indications for the use of aspirin during pregnancy are, however, the subject of much controversy. Since the first evidence of the obstetric efficacy of aspirin in 1985, numerous studies have tried to determine the effect of low-dose Acetyl salicylic acid (Aspirin) on the incidence of preeclampsia, with very controversial results [1-3]. Large meta-analyses including individual patient data have demonstrated that aspirin is effective in preventing preeclampsia in high-risk patients, mainly those with a history of preeclampsia. However, guidelines regarding the usage of Acetyl salicylic acid (Aspirin) to prevent preeclampsia differ considerably from one country to another. Screening modalities, target population, and aspirin dosage are still a matter of debate. In this review, we report the pharmacodynamics of aspirin, its main effects according to dosage and gestational age, and the evidence-based indications for primary and secondary prevention of preeclampsia [3, 4].

Pre-eclampsia is a multi-system disorder of pregnancy associated with hypertension and proteinuria. Its incidence varies between 2-10\%, depending on the population studied. Moreover, it is the second leading cause of direct maternal and foetal 
deaths in our country. Although, there is obvious predisposition in certain people to develop preeclampsia, the risk is $5-7 \%$ among primigravida women [3]. Further, while the origin of the pre-eclampsia remains unclear, it is believed that pre-eclampsia is associated with the deep placentation disorders. The physiological change-over of uterine spiral arteries between 8-16 weeks of gestation is the classical placental disorder associated with the pre-eclampsia [3]. Moreover; elevated platelet triggering is the set component of pathophysiology of pre-eclampsia. This may persuade to platelet utilization and ensuing the microvasculature's coagulation system set off, which sequentially leads to endothelial injury, vasospasm and end organ damage [3-5].

Currently, recommendation is to give low dose Acetyl salicylic acid (Aspirin) as early as 12-16 weeks of gestation to high risk pregnant women. However, first pregnancy itself is significant risk factor for preeclampsia development [2-5]. Therefore, in our study we assessed the effects of low dose Acetyl salicylic acid (Aspirin) in preventing pre-eclampsia among primigravida women when given in early weeks of gestation (8-16 weeks). This study may add up to enhance the evidence based on most advantageous timing of Acetyl salicylic acid (Aspirin) as well as use of aspirin as preventive medication among high-risk pregnant women.

\section{MATERIALS AND METHODS}

Subjects: A total number of 100 pre-eclampsia patients were recruited for this study. They were divided randomly in two groups as treatment group and control group. Selection of patients were carried out from the outpatient department and wards of Department of Obstetrics and Gynaecology of Mamata Medical College and General Hospital, Khammam, Telangana. Patients were diagnosed to have preeclampsia on the basis of presence of at lease two of the three criteria mentioned here: Blood Pressure (SBP more than $140 \mathrm{mmHg}$ and SBP more than $90 \mathrm{mmHg}$ ), Proteinuria (Extensive Urine analysis was considered), Oedema (All degree of water retention from excessive gain in weight to massive oedema were taken into account).

The 100 selected pre-eclampsia patients were divided randomly in two groups as treatment group and control group.

1. Treatment Group: These patients received in addition to conventional treatment (bed rest, sedative, antihypertensives), Acetyl salicylic acid (Aspirin) $75 \mathrm{mg} /$ day after breakfast to one week before estimated date of delivery.

2. Control Group: The control group included pre-eclampsia patients of same age and parity undergoing only conventional treatment of pre-eclampsia but no Acetyl salicylic acid (Aspirin) dose.

Examinations of patients: All the 100 selected pre-eclampsia patients were subjected to general, systemic, obstetrical and per vaginal examination wherever necessary.

Biochemical and Haematological Investigations were carried out by using the standard laboratory protocols.

Patients were followed in the out-patient's department on weekly basis and were admitted in the hospital, if their clinical condition required. They were treated according to the severity of disease. After admission to hospital they were treated with bed rest, salt restricted diet and sedatives. Acetyl salicylic acid was given to selected 50 patients only.

All the patients were delivered in the Department of Obstetrics and Gynaecology of Mamata Medical College and General Hospital.

Post-partum period: The patients were kept in the hospital for 5 days in vaginal (normal) delivery and for 8 days in caesarean section cases. Blood pressure, oedema, random urine protein and 24 hours urine protein were noted. Bleeding time, clotting time and platelet count were repeated 5 days after delivery.

Statistical analysis: Data analysis was done by using SPSS Package version. Simple proportions, mean, standard deviation and Chi-square test was used. Chi-square test was used to find out the association between two groups. P value of less than 0.05 is considered as statistically significant.

\section{RESULTS}

A total 100 patients of pre-eclampsia were selected from the outpatient department and wards of Department of Obstetrics and Gynaecology of Mamata Medical College and General Hospital.

The patients were divided randomly into equal number into treatment group and control group. Fifty patients who were selected as treatment group were given acetyl salicylic acid in a dose of $75 \mathrm{mg} /$ day as described earlier along with both the patients group also received the conventional treatment of pre-eclampsia.

The patients from treatment and control groups were matched similarly with respect to average age, gravidity, parity, number of previous bad obstetric experiences, oedema, proteinuria and blood pressure at the time of examination prior to recruit them in this study. 
Table-1: Exhibiting the distribution of patients as per the age group

\begin{tabular}{|c|c|c|c|c|c|}
\hline \multirow[t]{2}{*}{ Age groups (in years) } & \multicolumn{2}{|c|}{ Control Group $(n=50)$} & \multicolumn{2}{|c|}{ Treatment Group $(n=50)$} & \multirow[t]{2}{*}{ p Value } \\
\hline & Number & Percentage & Number & Percentage & \\
\hline$<20$ & 4 & 8 & 4 & 8 & \\
\hline $21-25$ & 16 & 32 & 16 & 32 & \\
\hline $26-30$ & 20 & 40 & 20 & 40 & \\
\hline $31-35$ & 10 & 20 & 10 & 20 & \\
\hline Mean \pm SD & \multicolumn{2}{|c|}{$24.81 \pm 3.12$} & \multicolumn{2}{|c|}{$25.21 \pm 4.29$} & $p>0.1$ \\
\hline
\end{tabular}

The treatment group who received acetyl salicylic acid (aspirin), the age ranged from 20-35 years with a mean age of $24.81 \pm 3.12$ years. Maximum number of cases belonged wot age group of 26-30 years. The treatment group who received acetyl salicylic acid (aspirin), the age ranged from 20-35 years with a mean age of $25.21 \pm 4.29$ years. Maximum number of cases belonged wot age group of 26-30 years.

Table-2: Exhibiting the clinical characteristics in treatment group and control group.

\begin{tabular}{|l|l|l|l|}
\hline Characteristics & Control Group (Mean \pm SD) & Treatment Group (Mean \pm SD) & p Value \\
\hline Weight (kg) & $58 \pm 2.19$ & $56 \pm 3.45$ & $\mathrm{p}=0.5$ \\
\hline Height (cm) & $156.32 \pm 5.36$ & $153 \pm 4.22$ & $\mathrm{p}>0.1$ \\
\hline Pulse (beats/min) & $71.28 \pm 8.24$ & $76.49 \pm 9.52$ & $\mathrm{p}>0.1$ \\
\hline Blood Pressure (mmHg) & & & \\
$\quad-\quad$ SBP & $148.32 \pm 10.36$ & $152.24 \pm 6.31$ & $\mathrm{p}>0.1$ \\
$-\quad$ DBP & $100.42 \pm 12.24$ & $102.54 \pm 14.28$ & $\mathrm{p}>0.1$ \\
\hline
\end{tabular}

There was no significant difference between control and treatment group in compared to weight, height, pulse rate and blood pressure.

Table-3: Exhibiting the haematological and biochemical profiles of treatment group and control group

\begin{tabular}{|l|l|l|l|}
\hline Variables & Control Group (Mean \pm SD) & Treatment Group $($ Mean \pm SD) & p Value \\
\hline Haemoglobin $(\mathrm{g} / \mathrm{dl})$ & $12.23 \pm 1.08$ & $10 \pm 1.22$ & $\mathrm{p}>0.1$ \\
\hline ESR $\left(\mathrm{mm}\right.$ in $1^{\text {st }}$ hour) & $10.54 \pm 2.47$ & $9.33 \pm 2.57$ & $\mathrm{p}>0.1$ \\
\hline Blood sugar $(\mathrm{mg} / \mathrm{dl})$ & $83.66 \pm 22.57$ & $86.32 \pm 17.55$ & $\mathrm{p}>0.1$ \\
\hline Blood sugar $(\mathrm{mg} / \mathrm{dl})$ & $32.46 \pm 12.33$ & $31.25 \pm 13.37$ & $\mathrm{p}>0.1$ \\
\hline Serum Uric Acid $(\mathrm{mg} / \mathrm{dl})$ & $5.27 \pm 1.33$ & $5.59 \pm 0.97$ & $\mathrm{p}>0.1$ \\
\hline Serum Creatinine $(\mathrm{mg} / \mathrm{dl})$ & $0.98 \pm 0.37$ & $0.96 \pm 0.47$ & $\mathrm{p}>0.1$ \\
\hline SGOT & $28.86 \pm 4.57$ & $26.84 \pm 5.17$ & $\mathrm{p}>0.1$ \\
\hline Urinary Proteins $(\mathrm{gms} / 24 \mathrm{hrs})$ & $2.46 \pm 1.63$ & $2.52 \pm 1.7$ & $\mathrm{p}>0.1$ \\
\hline
\end{tabular}

No statistically significant difference was observed between treatment and control groups in regard with haemoglobin, erythrocyte sedimentation rate, blood sugar, blood urea, serum uric acid, serum creatinine and 24 hours urine protein at the time of recruitment and selection of the patient for this study.

Table-4: Showing relationship between the gestational age, blood pressure profiles, platelet counts of treatment group and control group

\begin{tabular}{|l|l|l|l|l|l|l|}
\hline Group & $\begin{array}{l}\text { Gestational age at } \\
\text { the entry in the } \\
\text { study }\end{array}$ & \multicolumn{2}{|l|}{ Blood Pressure $(\mathrm{mm} \mathrm{Hg})$} & $\begin{array}{l}\text { Platelet Count } \\
\text { (lacs/cu.mm) }\end{array}$ \\
\cline { 3 - 7 } & & Before delivery & After delivery & \\
\cline { 3 - 7 } & & SBP & DBP & SBP & DBP & \\
\hline $\begin{array}{l}\text { Control } \\
\text { group }\end{array}$ & $30.23 \pm 3.21$ & $134.42 \pm 13.24$ & $84.36 \pm 13.29$ & $126.38 \pm 7.56$ & $82.71 \pm 5.37$ & $2.23 \pm 0.98$ \\
\hline $\begin{array}{l}\text { Treatment } \\
\text { group }\end{array}$ & $29.17 \pm 2.41$ & $138.52 \pm 10.57$ & $86.28 \pm 11.21$ & $129.23 \pm 8.21$ & $83.57 \pm 6.27$ & $2.20 \pm 0.87$ \\
\hline
\end{tabular}

No statistically significant difference was observed between control and treatment group in regarding with gestational age, blood pressure profiles and platelet count. 
Table-5: Exhibiting the maternal outcome in treatment group and control group

\begin{tabular}{|l|l|l|l|l|}
\hline \multirow{2}{*}{ Variables } & \multicolumn{2}{|l|}{ Control Group (Mean \pm SD) } & \multicolumn{2}{l|}{ Treatment Group (Mean \pm SD) } \\
\cline { 2 - 5 } & Number & Percentage & Number & Percentage \\
\hline Mode of delivery & & & & \\
$\quad$ Vaginal & 34 & 68 & 37 & 74 \\
$\quad$ - Caesarean section & 16 & 32 & 13 & 26 \\
\hline Maternal mortality & 2 & 4 & 1 & 2 \\
\hline Postpartum-eclampsia & 2 & 4 & 3 & 6 \\
\hline
\end{tabular}

Caesarean section delivery was carried out in 13 patients of treatment group and 16 patients of control group. Rest of the patients delivered normally per vaginally. Maternal mortality was $4 \%$ in control group while it was $2 \%$ in treatment group. Postpartumeclampsia was observed in 2 patients from control group and 3 patients from treatment group. No excessive bleeding occurred during vaginal delivery or caesarean section in the treatment group. No other haemorrhagic complications were observed in any of the group.

\section{DISCUSSION}

The present study was undertaken to evaluate the benefit of low dose acetyl salicylic acid (75 mg per day) on foetal and maternal outcome in pre-eclampsia. The rationale of use Acetyl salicylic acid (Aspirin) in pre-eclampsia rests upon the involvement of platelets and prostaglandins in its pathogenesis. Various haematological, biochemical parameters in preeclampsia were also studied.

In this study maximum number of preeclampsia patients $(50 \%)$ belonged to age group of 2630 years. The age of women presenting with pregnancy varies according to social background and geographical region, otherwise there is not much difference in their presentation. The treatment group who received acetyl salicylic acid (aspirin), the age ranged from 20-35 years with a mean age of $24.81 \pm 3.12$ years. Maximum number of cases belonged wot age group of 26-30 years. The treatment group who received acetyl salicylic acid (aspirin), the age ranged from 20-35 years with a mean age of $25.21 \pm 4.29$ years.

Comparative evidence regarding age of presentation have been reported by various investigators [6-9]. Further, in the current study most of the women were house wives, and had low monthly income. The relationship of low socioeconomic status and less influential social background has a significance in the development of hypertension in general patients, as far as pregnancy induced hypertension is concerned there is a need to work on this type of associations. Further, investigators have reported that when Acetyl salicylic acid (Aspirin) is given early on in the pregnancy it reduces the risk of pre-eclampsia with greater impact and intensity [10-12]. Most of the current study women presented between 13 and 16 weeks of gestation, whereas some presented earlier.
Moreover, Cadavid AP witnessed that aspirin administration early in the pregnancy significantly reduced pre-eclampsia, they reported that among women with pre-eclampsia delivering before 37 weeks of gestation, in the observation arm there were $0.83 \%$ cases with pre-eclampsia compared to only $0.37 \%$ in the interventional arm [8]. The value of Acetyl salicylic acid (Aspirin) is accepted by a number of national and international institutions who recommend prescription to high risk groups [12-15].

In our study, we found a significant decrease in caesarean sections in the Acetyl salicylic acid (Aspirin) plus conventional therapy treated group than in conventional therapy group. Many others have also witnessed a similar trend of prior aspirin treatment which shows a positive effect.

In our study, low dose Acetyl salicylic acid (Aspirin) has significant effect on pregnant women in terms of prevention of pre-eclampsia. Moreover, the glycaemic and renal parameters in terms of blood pressure, urinary albumin and uric acid also remained within normal range in Acetyl salicylic acid (Aspirin) group when compared with those control group.

This shows that low dose Acetyl salicylic acid (Aspirin) when given early in pregnancy has multiple controls and not only the onset of preeclampsia is averted, the glycaemic and renal function is also kept normal thus, giving ample chance to the mother and foetus to live and grow healthy. This data supports the early initiation of aspirin among pregnant women in preventing pre-eclampsia development.

\section{CONCLUSIONS}

Our study highlights the beneficial effect of low-dose acetyl salicylic acid in decreasing hypertension and proteinuria. This study also confirms the efficacy of acetyl salicylic acid in decreasing caesarean section, maternal mortality and morbidity. Low dose of acetyl salicylic acid is not associated with any demonstrated adverse maternal or foetal effect. Acetyl salicylic acid at the dose of $75 \mathrm{mg} /$ day is highly efficacious and safe in pre-eclampsia. Good medical tolerance without serious side effects as well as low cost of therapy will be an additional advantage. 


\section{REFERENCES}

1. World Health Organization (WHO). (2011). WHO recommendation for prevention of preeclampsia and eclampsia.

2. Duley, L., Henderson-Smart, D. J., Meher, S., King, J. F. (2007). Antiplatelet agents for preventing pre-eclampsia and its complications. In: The Cochrane Collaboration (ed). Cochrane Database Syst. Rev. Wiley, Chichester.

3. Amin, O., Tasnim, N., \& Naeem, S. (2020). Prevention of pre-eclampsia with low dose aspirin in primigravida. MOJ Women's Health. 9(1):2832.

4. Abdelouahab, B., \& Daniel, V. (2011). Prevention of gravidic endothelial hypertension by aspirin treatment administered from the 8th week of gestation. Hypertension Research. 34:1116-1120.

5. Bartsch, E., Medcalf, K. E., Park, A. L., \& Ray, J. G. (2016). Clinical risk factors for pre-eclampsia determined in early pregnancy: systematic review and meta-analysis of large cohort studies. Bmj, 353 .

6. Roberge, S., Villa, P., Nicolaides, K., Giguère, Y., Vainio, M., Bakthi, A., ... \& Bujold, E. (2012). Early administration of low-dose aspirin for the prevention of preterm and term preeclampsia: a systematic review and meta-analysis. Fetal diagnosis and therapy, 31(3), 141-146.

7. Vainio, M., Kujansuu, E., Iso-Mustajärvi, M., \& Mäenpää, J. (2002). Low dose acetylsalicylic acid in prevention of pregnancy-induced hypertension and intrauterine growth retardation in women with bilateral uterine artery notches. BJOG: an international journal of obstetrics and gynaecology, 109(2), 161-167.

8. Yifru, B. (2016). No hypertensive disorder of pregnancy; no preeclampsia eclampsia; no gestational hypertension; no hellp syndrome. Vascular Disorder of Pregnancy Speaks for All. Ethiop J Health Sci. 26(2);177-186.

9. Cadavid, A. P. (2017). Aspirin: the mechanism of action revisited in the context of pregnancy complications. Front Immunol. 8:261.

10. Woelkers, D., Barton, J., von Dadelszen, P., \& Sibai, B. (2015). The revised 2013 ACOG definitions of hypertensive disorders of pregnancy significantly increase the diagnostic prevalence of preeclampsia. Pregnancy Hypertens Int J Womens Cardiovasc Health. 5:38.

11. von Dadelszen, P., \& Magee, L. A. (2014). Preeclampsia: an update. Curr Hypertens Rep. 16:114.

12. Say, L., Chou, D., Gemmill, A., Tunçalp, Ö., Moller, A. B., Daniels, J., ... \& Alkema, L. (2014). Global causes of maternal death: a WHO systematic analysis. The Lancet Global Health, 2(6), e323-e333.

13. Mitchell, J. A., Ahmetaj-Shala, B., Kirkby, N. S., Wright, W. R., Mackenzie, L. S., Reed, D. M., \& Mohamed, N. (2015). Role of prostacyclin in pulmonary hypertension. Global Cardiology Science and Practice, 2014(4), 53.

14. Patrick, J., Dillaha, L., Armas, D., \& Sessa, W. C. (2015). A randomized trial to assess the pharmacodynamics and pharmacokinetics of a single dose of an extended-release aspirin formulation. Postgrad Med. 127:573-80.

15. Roberge, S., Nicolaides, K. H., Desmers, S., Hyett, J., Chaillet, N., \& Bujold, E. (2017). The role of aspirin dose on the prevention of preeclampsia and fetal growth restriction: systematic review and meta-analysis. Am J Obstet Gynecol. 216(110-120):e6. 